\title{
The simulation of the observation data in predicting tidal patterns using the Admiralty method in Dumai's harbour
}

\author{
Andy Hendri ${ }^{1 *}$, Manyuk Fauzi $^{1}$, Rosmiati Ahmad ${ }^{1}$, Andarsin Ongko ${ }^{1}$, and Fajri Almanna ${ }^{1}$ \\ ${ }^{1}$ Department of Civil Engineering, Universitas Riau, Pekanbaru, Indonesia
}

\begin{abstract}
In this paper, we have discussed the tidal analysis conducted using the Admiralty method with 15 days of tidal data as the research object. Due to the long tidal data period, the analysis was conducted in order to determine the proper time to collect the data for future tidal predictions. This data has to be adequate for its realisation in reality. The used data was collected from the Geospatial Information Association and the location of this research study was Dumai's Harbour. The study started on July $13^{\text {th }}, 2014$ and ended on December $8^{\text {th }}, 2014$. For verification, the used data started from June $13^{\text {th }}, 2016$ and ended October $31^{\text {st }}, 2016$. From the 135 simulations, we determined that the magnitude of the Root Mean Square Error (RMSE) was 106.2. In order to produce well-predicted tidal results, the collection of the tidal data was best started during the phase of the crescent moon (which begins on the $24^{\text {th }}$ based on the Hijriah calendar). On these dates, the RMSE reached the lowest value with a magnitude of 74.76. This result could be used as a reference when choosing the proper time to collect the observation data and also for predicting the tidal patterns at the location.
\end{abstract}

\section{Introduction}

Tidal phenomenon frequently occurs in Indonesia. Indonesia has a total of 13,466 islands, $1,922,570 \mathrm{~km}^{2}$ of land and 3,257,483 $\mathrm{km}^{2}$ of water [1]. Dumai is one of the cities in Riau, which is located on the East coast of Sumatra Island, right on the international Malacca lane. This has caused trading opportunities to be boosted and has created a higher potential for seaport development. The harbor of Dumai is the main port in Riau Province, which is used as a connecting port for import and export activities as well as passenger transportation.

When managing any activities in a harbor, some oceanographic knowledge is required. This includes tidal knowledge. Information on tidal patterns is necessary to determine the peak elevation of the waves, the dimensions of the dock, the length of the retaining buoys, the depth of the shipping lane and the harbor pool, and so on [2]. However, the availability of tidal measurements is sometimes limited, so oceanographers need to conduct tidal

*Corresponding author: andy.hendri@lecturer.unri.ac.id 
predictions. The most commonly used methods are the Admiralty method and the Least Square method. The research that was conducted in this research was a case study at Tanjung Buton Port, Siak Regency. The research was conducted by [3] using the Least Square method using the tidal data for 15 days, from the 8th to the 22nd August 2004. This yielded a tidal forecast with an average error rate of $240.97 \%$. Furthermore, [4], in the same case study, used the Admiralty method which resulted in an average error rate of $22.41 \%$. However, this research did not discuss the effect of early variations in the observational data. [5] conducted a research study on the influence of the early tidal data using the Admiralty method at Apra Harbour, Guam, in the Mariana Islands using the Hijriah calendar. [6] have performed some simulations by using Artificial Neural Network (ANN) and obtained a well-predicted data with a very low error rate. However, this method is not suitable for long interval tidal data

The preparation of the tide measurement data based on the Hijriah calendar will affect the results of the tidal harmonic constant calculations. The grouping of the data based on the Hijriah calendar results in a relatively stable deviation value for the harmonic constants and forms the same pattern. In contrast, when it is based on the Christian calendar, it gives a large deviation amplitude value for the harmonic constants [7].

In this research, the Admiralty method was used to perform the calculations. This method produced a lower average error rate than the Least Square method. The data in this research was the observation data over approximately two years, observed hourly obtained from the Geospatial Information Agency (GIA). The data was simulated using some initial variations in the observational data based on the Hijriah calendar. The location of the data measurements in this research was at the coordinates 1041'20.88 "Northern Latitude and 1010 26'38.161" Eastern Longitude. Through Google Maps, it can be seen that the location is located in Dumai Port, Dock C, Pelindo in Riau.

\section{Literature review}

Tidal patterns are the fluctuations of the sea water level as a function of time due to the gravitation power from outer space, related to the solar and lunar influence on the mass of water on the Earth. Although the moon's mass is much smaller than the mass of the sun, its distance from the Earth is much less, and therefore it has a greater influence.

Generally, the tides in different regions can be categorized into four types; semi-diurnal, diurnal, mixed prevailing semi-diurnal, and mixed prevailing diurnal. The different types of tide can be observed in Fig. 1.

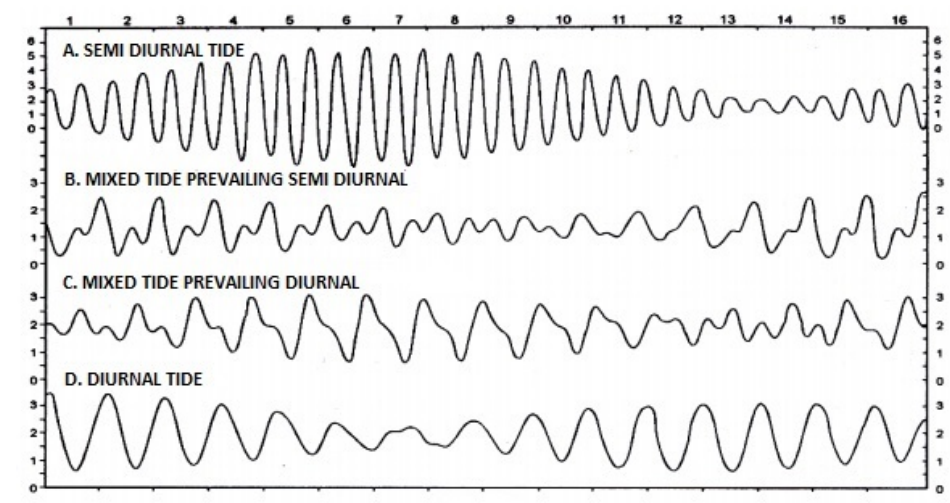

Fig. 1. Types of tide [2]. 
The different tidal types are due to the influence of the moon and the sun and consist of two types, namely the spring tide and the neap tide. The spring tide occurs when the earth, the moon, and the sun are in a straight line. This condition creates a pull force between the three of them, with one strengthening the other. In this case, the tides are excessively powerful. The neap tide occurs when the sun and moon have a perpendicular position with the earth. This reduces the gravitation power between them, which results in a lower tidal height. This can be observed in Fig. 2.

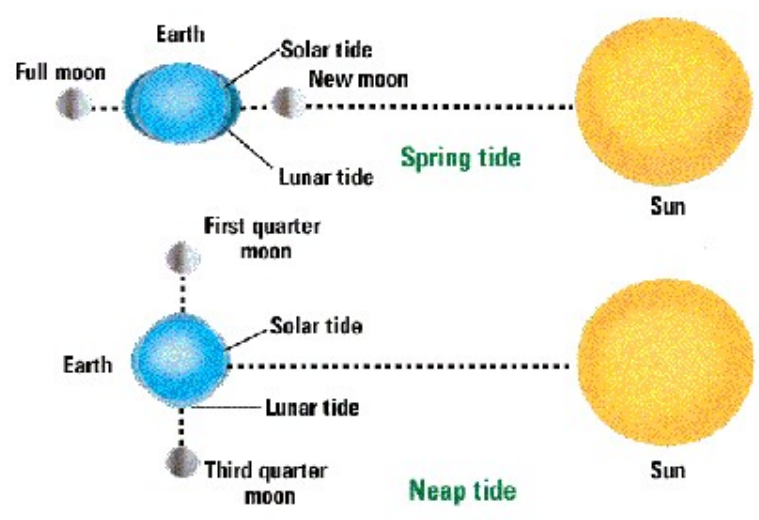

Fig. 2. Spring tide and neap tide [8].

Some terms that are widely used in coastal and port building planning include Mean High Water Level (MHWL) and Highest High Water Level (HHWL), which are used to determine the peak-breaking elevations, docks, long buoy chains, etc. The Lowest Low Water Level (LLWL) is needed to determine the depth of the shipping and harbor pools. The water level itself is influenced by several components of the tides themselves, i.e. Principal Lunar (M2), Principal Solar (S2), Large Lunar Elliptic (N2), Lunar Solar (K2), Lunar Solar Diurnal (K1), Principal Solar Diurnal (O1), Large Lunar Elliptic (P1), Lunar Monthly (M1), Solar Semidiurnal (Mm), and Shallow Water (M4 and MS4).

The Admiralty method is the method used to calculate the harmonic tidal constants from the observation of the sea level every hour for 15 to 29 days. The Admiralty method consists of eight arrangement groups. The final result of the Admiralty method calculation is the amplitude and phase difference of each separate tidal component. After the amplitude (A) and phase (g0) of each tidy component have been obtained, the next step is to calculate the forecast elevation of the tide, which is the reduction of the tidal elevation of the observation from the sum of the coefficient of each tidal component.

The Formzahl number $(\mathrm{F})$ is the division of the amplitude of the main single tidal constant from the main double tidal constant amplitude. From the calculation of Formzahl number, we will be able to determine the type of tide. There are four different types of tidal pattern; semi-diurnal tide $(\mathrm{F} \leq 0.25)$, mixed tide prevailing semi-diurnal $(0.25<\mathrm{F} \leq 1.5)$, mixed tide prevailing diurnal $(1.5<\mathrm{F} \leq 3)$, and diurnal tide $(\mathrm{F}>3)$.

Root Mean Square Error (RMSE) is an alternative solution used to evaluate forecasting techniques to measure the accuracy of the forecast result of a particular model. The RMSE is the average value of the sum of the square error; it can also indicate the measurement of the error generated by a forecast model. A low RMSE value indicates that the variation of the value generated by the forecast model approaches the variation of the observed value. 


\section{Research methodology}

\subsection{Research data}

In this research, the data used secondary data in the form of hourly tidal data obtained from the Geospatial Information Agency (GIA). The data used for the simulation was collected between July $13^{\text {th }}, 2014$ and December $8^{\text {th }}, 2014$ (16 Ramadhan $1435 \mathrm{H}$ to 16 Shafar 1436 $\mathrm{H})$, while the data used for the verification was the simulation data itself. The data that was used was from between June $16^{\text {th }}, 2016$ and October $31^{\text {st }}$, 2016 (11 Ramadan $1437 \mathrm{H}$ to 1 Shafar $1438 \mathrm{H})$.

\subsection{Research location}

The location of the data measurement in this research was at coordinates 1041'20.88" Northern Latitude and 1010 26'38.161" Eastern Longitude. Using Google Maps, it can be seen that the location was Dumai Port-Dock C, Pelindo, Riau.

\subsection{Tidal analysis}

The tidal analysis in this research used the Admiralty method, with the observation data collected hourly for 15 days. The verification data used was the simulation data and the data used from June $16^{\text {th }}, 2016$ through to October $31^{\text {st }}, 2016$ (11 Ramadhan $1437 \mathrm{H}$ to 1 Shafar $1438 \mathrm{H})$. The output of the calculation and the processing of the tidal data was the amplitude (A) and phase difference (g) of each tidal component, the Formzahl number (F) and important water elevations that can be used as the planning reference in the research area.

\section{Results and discussion}

\subsection{Error rate}

The error rate in this research was calculated using the Root Mean Square (RMSE) equation. The results could be observed in Fig. 3 and 4 below.

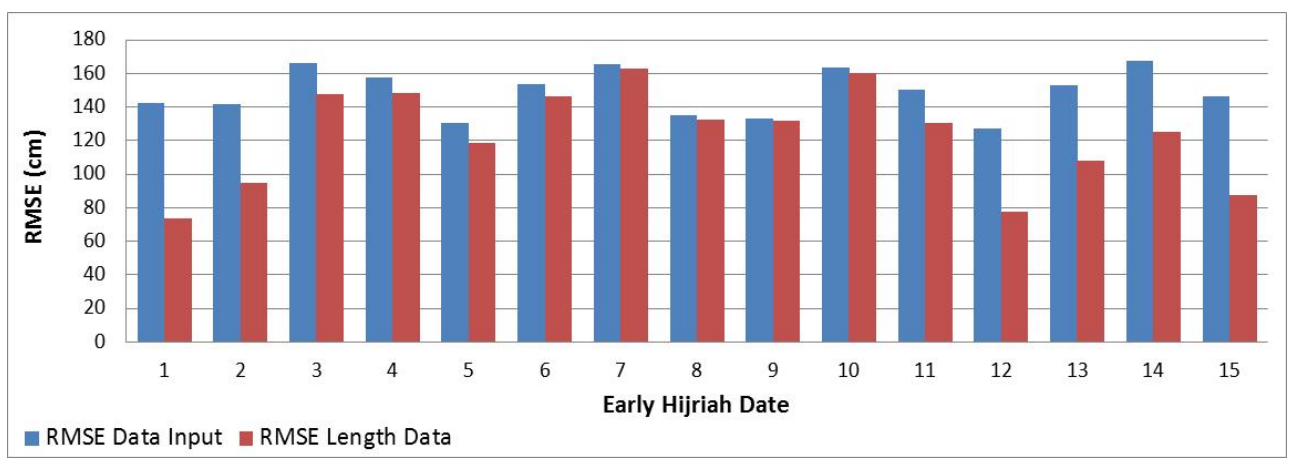

Fig. 3. Graph of the verified average RMSE values from the $1^{\text {st }}$ to the $15^{\text {th }}$ Hijriah date.

According to Fig. 3, the lowest average RMSE value for the verified results in the simulation data was $76.40 \mathrm{~cm}$. This value was found in the data from the early $12^{\text {th }}$ date of the Hijriah calendar in phase 4 (the initial humpback). As in Fig. 4, it can be seen that the 
smallest average RMSE value of the verified results was between June $16^{\text {th }}, 2016$ and $31^{\text {st }}$ October 2016 (11 Ramadhan $1437 \mathrm{H}$ to 1 Shafar $1438 \mathrm{H}$ ), which was $74.76 \mathrm{~cm}$. The mean value of the smallest RMSE was found in the data of the early $24^{\text {th }}$ date of the Hijriah calendar in phase 7 (during the crescent moon). This suggested that the proper time for collecting the observation data was right before the full moon phase and after the full moon phase. These results can be used as an early reference to find the proper time to collect the observation data to predict tides in the research area.

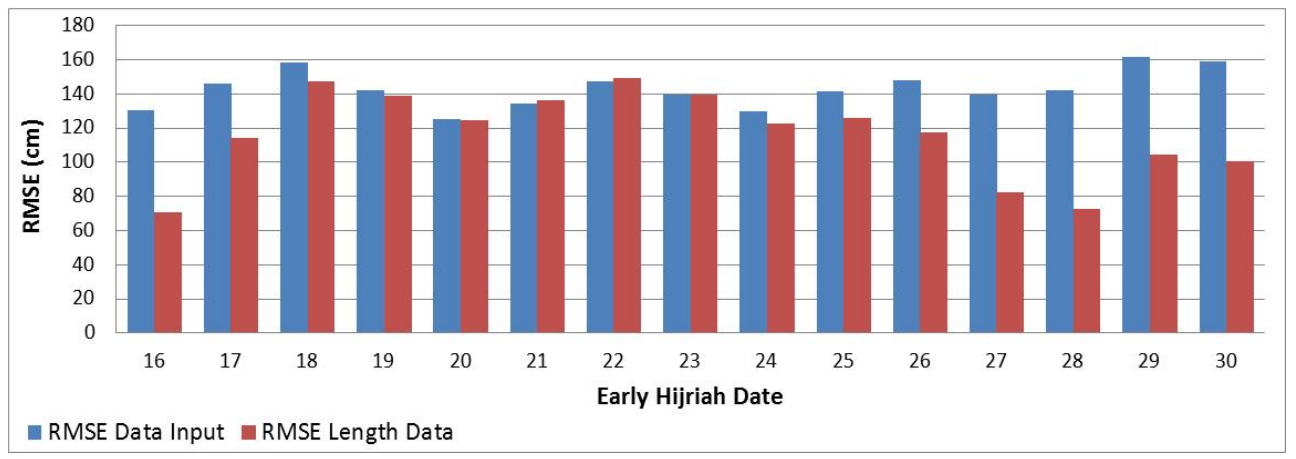

Fig. 4. Graph of the verified average RMSE values from the $16^{\text {th }}$ to the $30^{\text {th }}$ Hijriah date.

\subsection{Tidal components}

The obtained tidal component value during the observation time with the lowest RMSE value can be used as a reference to determine the tidal forecast elevation in the research area. The mean amplitude value of the tidal components of M2, S2, N2, K2, K1, O1, P1, and MS4 can be seen in Fig. 5, which shows that the overall value was relatively stable. However, the value of M4 is significantly different. M4 was part of a shallow water component with a non-linear variable due to the influence of the weather.

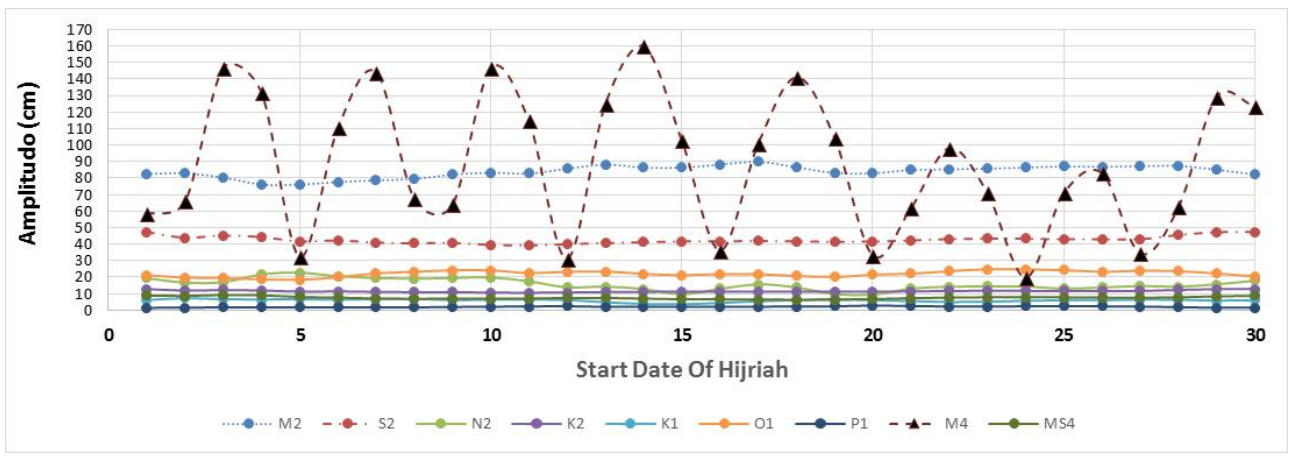

Fig. 5. Average amplitude value of each tidal component.

\subsection{Type of tides}

In order to determine the different types of tide in the research area, the value of Formzahl (F) needed to be found. This value aided us in classifying the tides. According to Fig. 6 and 7, the average F value in this research was $\leq 0.25$. This classified the type of tide as semi-diurnal. This also aligns with the statement made by [2], who declared the place as being a semi-diurnal tide area. The difference in the Formzahl value of each month was not significant. 


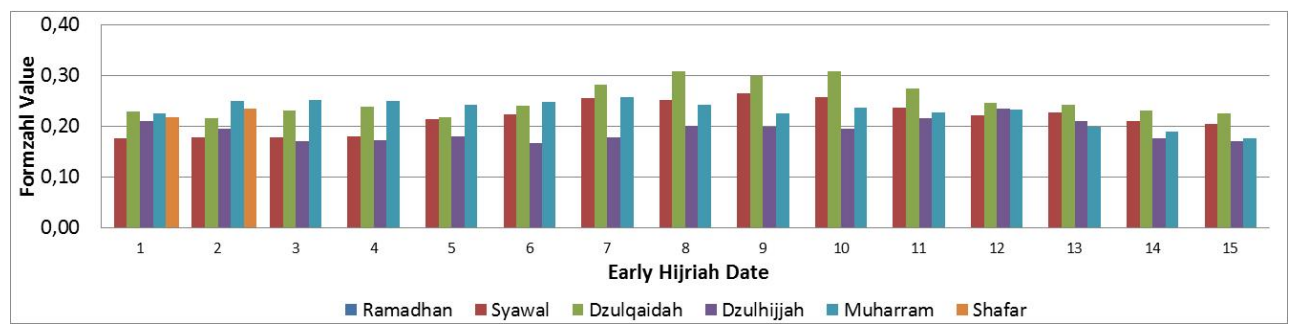

Fig. 6. Formzahl graph from the $1^{\text {st }}$ to the $15^{\text {th }}$ in the Hijriah Calendar.

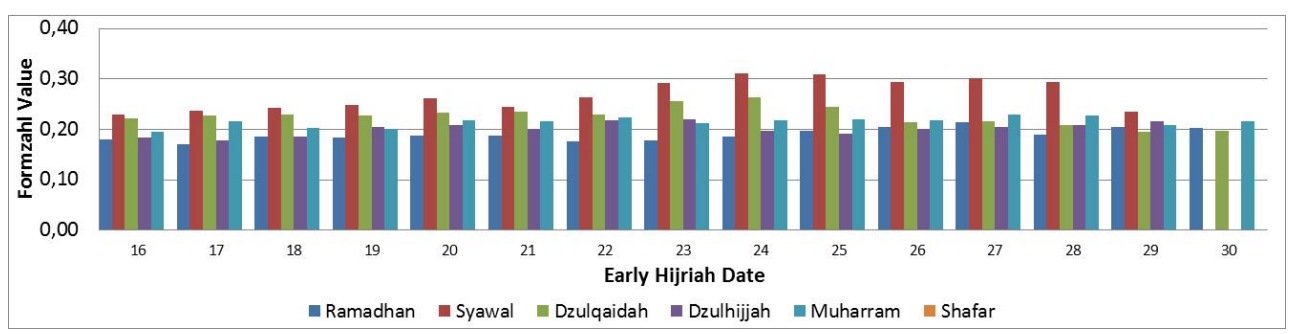

Fig. 7. Formzahl graph from the $16^{\text {st }}$ to the $30^{\text {th }}$ in the Hijriah Calendar.

\section{Conclusions}

After the analysis and discussion were completed, we concluded that the lowest average RMSE value in the verification of the results was $76.40 \mathrm{~cm}$. This value was found on the beginning date (12 $12^{\text {th }}$ in the Hijriah Calendar), which was in phase 4 (the initial humpback). The lowest average RMSE value in the verified data was between June $16^{\text {th }}, 2016$ and October 31 $1^{\text {st }}, 2016$ (11 Ramadhan $1437 \mathrm{H}$ to 1 Shafar $1438 \mathrm{H}$ ), which was $74.76 \mathrm{~cm}$. This value was found on the beginning date of the $24^{\text {th }}$ of the Hijriah calendar, which was in phase 7 (crescent). To collect the proper observation data, the best timing was either near to the full moon phase or after the full moon phase. The dominant Formzahl number was obtained at the Pelabuhan Dumai-D Pelindo location, classified as $\mathrm{F} \leq 0.25$. This indicated that the tides in this area were classified as a daily double-tide (semi-diurnal tide). In other words, at least two tides happened at the same elevation.

\section{References}

1. R. Lasabuda, J. of Platax Science 1 (2013)

2. B. Triatmodjo, Teknik pantai, (Beta Offset, Yogyakarta, 1999)

3. R. Habibie, Prakiraan pasang surut dengan metode last square: studi kasus pelabuhan Tanjung Buton (Universitas Riau, Pekanbaru, 2008)

4. I. Puspa, Prakiraan pasang surut dengan metode Admiralty (Universitas Riau, Pekanbaru, 2008)

5. A. Hendri, M. Fauzi, W. Safitri, J. of Science and Tech. 1 (2012)

6. A. Hendri, I. Suprayogi, M. Zulfakar, A. Ongko, Proc. of CSAI 2017 (2017)

7. Salnuddin, I.W. Nurjaya, I. Jaya, N. Natih, Indonesian J. of Marine Sci. 20 (2015)

8. F. Jochem, Tides. Available at: http://www.jochemnet.de/fiu/OCB3043_12.html (2003) 